\title{
FEMORAL MECHANICAL-BIOLOGICAL GRAFT FIXATION IN ACL RECONSTRUCTION IN YOUNG PATIENTS
}

doi: $10.1590 / \mathbf{S 1 8 0 7 - 5 9 3 2 2 0 1 0 0 0 0 3 0 0 0 1 9}$

João Ellera Gomes, Cássio Alves Konrath

\section{INTRODUCTION}

ACL reconstructions in young, skeletally immature athletes are potentially harmful, both for the tibial and femoral growth plates. ${ }^{1,2}$

Over the last decade, the results of non-operative treatments have been poor, but several authors now recommend that skeletally immature patients undergo surgery, ${ }^{3-5}$ despite its potential risks. ${ }^{6}$

Observation alone may also be harmful to the health of the knee joint, ${ }^{7}$ because young athletes tend to be less cooperative and frequently resume the practice of rotational sports even against medical advice. ${ }^{8}$ Therefore, a consensual decision should be made by the parents, the athlete and the medical team before other structures of the joint (e.g., articular cartilage or any of the menisci) are irreversibly affected. ${ }^{7}$

\section{BACKGROUND}

Among the many surgical techniques for ACL reconstruction, ${ }^{8-12}$ the "over-the-top" technique is often chosen for young patients because it preserves the open femoral growth plate. ${ }^{13}$ This plate is usually fixed with spiked washers that do not promote long-term biological fixation. A different method could be used to insert the tendon graft into the lateral femoral condyle and achieve permanent tendonbone integration. Such a method should combine intrinsic mechanical strength capable of holding the tendon graft immediately after its insertion with the capacity to biologically

Department of Surgery, Medical School, Universidade Federal do Rio Grande do Sul (UFRGS) - Porto Alegre/RS, Brazil.

Email: joelgo.voy@terra.com.br

Tel.: 55513328.2828 induce tendon-bone integration over time. This combination makes the system independent of the hardware used in the long term. Such a result can be achieved with the use of custom-made trephines, as described below.

\section{SURGICAL TECHNIQUE}

The semitendinosus and gracilis tendons are obtained as usual through a small incision in the anteromedial surface of the proximal tibia.

After removing all muscle tissue, the tendons are folded over themselves, and the free ends are stitched together. An 8 -mm initial tibial tunnel, $1.5 \mathrm{~cm}$ in length, is drilled to a point just before entering the tibial growth plate. This tunnel is perforated with a trephine that removes a $1-\mathrm{cm}$ bone plug.

The tunnel is drilled up to the tibial crest with a $6-\mathrm{mm}$ drill. The tendons are passed through the joint and over the top of the lateral femoral condyle and exit on the lateral side.

At this point, an entrance hole parallel to the femoral growth plate is made through a lateral $2.5-\mathrm{cm}$ skin incision with a 4-mm drill. Using a guide pressed against this hole, a $1.2-\mathrm{cm}$ wide and $0.5-\mathrm{cm}$ long bone washer is cut with another specially designed trephine (Figure 1, A and B).

The lower side of the hole is trimmed to avoid a possible sharp, harmful edge. After that, a spongious screw with a metal washer and the bone washer are passed through the two tendon loops (Figure 2, A and B). The bone washer presses the tendons against the bottom of the larger hole when connected to the screw (Figure 3, A and B).

In contrast to their use in skeletally mature adult patients, the screws are not deeply inserted into the lateral femoral condyle across open growth plates in young athletes (Figures 4 and 5); they may be easily removed under local anesthesia when growth is complete. 


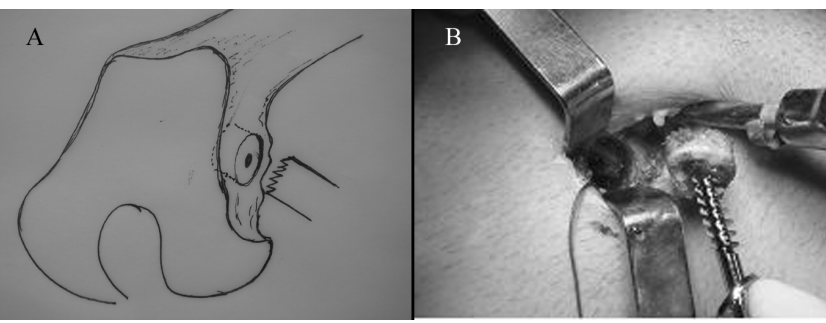

Figure 1 - (A) Cutting of the bone washer with a special trephine parallel to the growth plate. (B) Removal of the bone washer with the spongious screw.

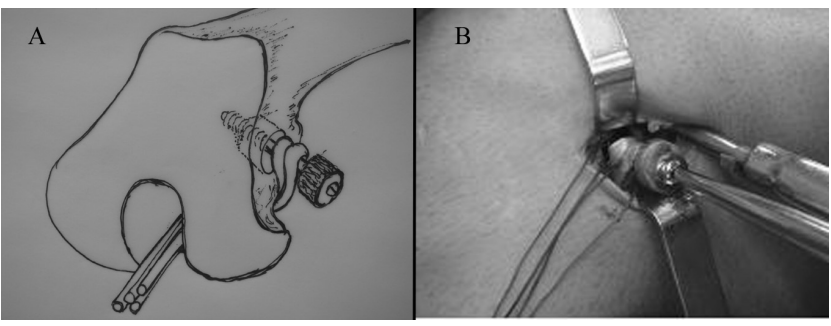

Figure 2 - Drawing (A) and picture (B) of the spongious screw with the metal washer and the bone washer being passed through the two tendon loops after countouring the lateral femoral condyle in an "over-the-top" fashion.

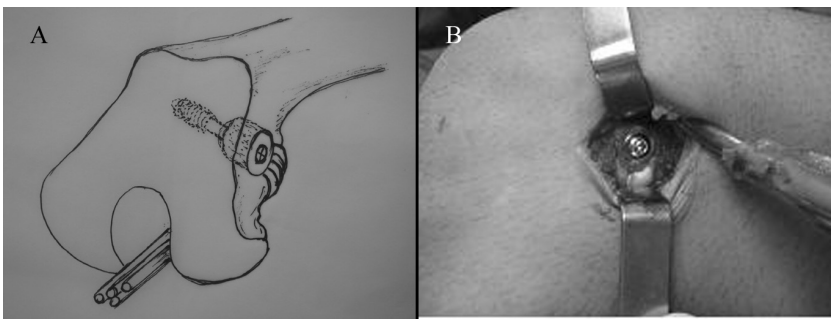

Figure 3 - (A) Drawing of the bone washer pressing the tendons against the bottom of the larger hole when connected to the screw. (B) Picture of final fixation.

The distal end of the tendon grafts is then fixed to the medial tibial metaphysis with a cortical screw and an AO plastic spiked washer. Finally, the cylindrical bone plug is pressed against the tendons at the entrance of the tibial hole, and both ends of the ACL graft are fixed with the screw. Full weight-bearing activity without crutches is allowed six days after surgery.

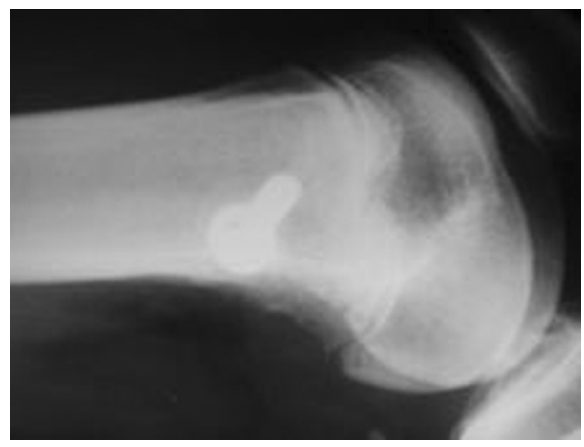

Figure 4 - The screw in its place of attachment.

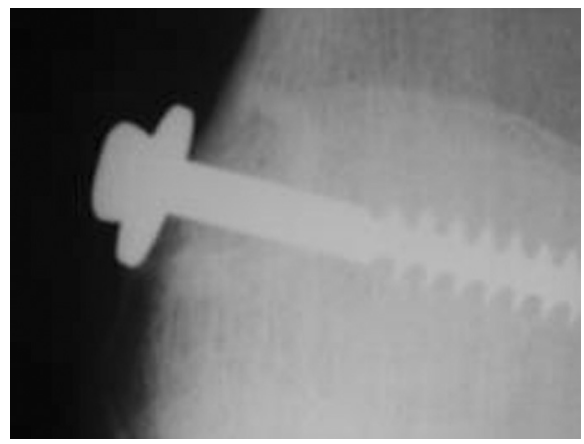

Figure 5 - Image of the screw in the bone one year after surgery.

\section{RESULTS}

This surgical technique was used in 12 patients with fully satisfactory results. All athletes reached skeletal maturity without signs of angle deformity or an unexpected shortening of the operated limb.

Even the required second lateral incision was considered acceptable by the patients because of the advantage of not having to wait for reconstruction.

\section{CONCLUSION}

This technique provides not only strong, immediate mechanical fixation but also long-term biological fixation supported by bone growth around the tendon graft.

\section{REFERENCES}

1. Aronowitz ER, Ganley TJ, Goode JR, Gregg JR, Meyer JS. Anterior cruciate ligament reconstruction in adolescents with open physes. Am J Sports Med. 2000;28:168-75.

2. Bales CP, Guettler JH, Moorman CT 3rd. Anterior cruciate ligament injuries in children with open physes: evolving strategies of treatment. Am J Sports Med. 2004;32:1978-85.
3. Andrews M, Noyes FR, Barber-Westin SD. Anterior cruciate ligament allograft reconstruction in the skeletally immature athlete. Am J Sports Med. 1994;22:48-54.

4. Pressman AE, Letts RM, Jarvis JG. Anterior Cruciate Ligament tears in children: an analysis of operative versus nonoperative treatment. J Pediatr Orthop. 1997;17:505-11. 
5. Shelbourne KD, Gray T, Wiley BV. Results of transphyseal anterior cruciate ligament reconstruction using patellar tendon autograft in tanner stage 3 or 4 adolescents with clearly open growth plates. Am J Sports Med. 2004;32:1218-22.

6. Wester W, Canale S, Dutkowsky J, Warner WC, Beaty JH. Prediction of angular deformity and leg-length discrepancy after anterior cruciate ligament reconstruction in skeletally immature patients. J Pediatr Orthop. 1994;14:516-21.

7. Woods GW, O'Connor DP. Delayed anterior cruciate ligament reconstruction in adolescents with open physes. Am J Sports Med. 2004;32:201-10.

8. Guzzanti V, Falciglia F, Stanitski CL. Preoperative evaluation and anterior cruciate ligament reconstruction technique for skeletally immature patients in Tanner stages 2 and 3. Am J Sports Med. 2003;31:941-8.
9. Anderson AF, Anderson CN. Hamstring anterior cruciate ligament reconstruction in the skeletally immature patient. Tech Orthop. $2005 ; 20: 314-22$.

10. Guzzanti V, Falciglia F, Stanitski CL. Physeal-sparing intraarticular anterior cruciate ligament reconstruction in preadolescents. Am J Sports Med. 2003;31:949-53.

11. Kocher MS, Garg S, Micheli LJ. Physeal sparing reconstruction of the anterior cruciate ligament in skeletally immature prepubescent children and adolescents. J Bone Joint Surg Am. 2005;87:2371-9.

12. Brand J Jr, Weiler A, Caborn DN, Brown CH Jr, Johnson DL. Graft fixation in cruciate ligament reconstruction. Am J Sports Med. 2000;28:761-74.

13. Kim SH, Ha KI, Ahn JH, Chang DK. Technical note anterior cruciate ligament reconstruction in the young patient without violation of the epiphyseal plate. Arthroscopy. 1999;7:792-5. 